Research Article

\title{
Drug utilization study of co-administration of nonsteroidal anti- inflammatory drugs and gastroprotective agents in an orthopaedics outpatients department of a tertiary care hospital in West Bengal
}

\author{
Ajay Kumar ${ }^{\mathrm{a}}$, Chanchal Kumar Dalai ${ }^{\mathrm{b}}$, Amit Kumar Ghosh ${ }^{\mathrm{c}}$, Madhumita Ray ${ }^{\mathrm{d}}$
}

\begin{abstract}
${ }^{a}$ Department of Orthopaedics, College of Medicine and JNM Hospital, Kalyani, Nadia, West Bengal, Pin-741235, India

${ }^{\mathrm{b}}$ Department Of Pharmacology, College of Medicine and JNM Hospital, Kalyani, Nadia, West Bengal, Pin-741235, India

${ }^{\mathrm{c}}$ Department of Pharmacology, R.G. Kar Medical College \& Hospital, Kolkata, West Bengal, Pin-700004, India

${ }^{\mathrm{d}}$ Department of Anesthesiology, Calcutta National Medical College \& Hospital, Kolkata, West Bengal, Pin-700014, India
\end{abstract}

Received: 31 December 2012

Accepted: 27 January 2013

*Correspondence to:

Dr. Amit Kumar Ghosh,

Email: 21111969amitghosh@gmail.com

(C) 2013 Kumar A et al. This is an open-access article distributed under the terms of the Creative Commons Attribution License, which permits unrestricted use, distribution, and reproduction in any medium, provided the original work is properly cited.

\begin{abstract}
Background: Non steroidal anti-inflammatory drugs (NSAIDs) are the commonly prescribed analgesic in the orthopaedics department. NSAIDs are prescribed for a long period in both acute condition (like fracture of bones, muscle injury, postoperative procedures etc) or chronic conditions (osteoarthritis etc). However, they have many adverse effects, especially gastrointestinal toxicity when use regularly. For this reason NSAIDs are frequently co-prescribed with gastro protective agents. Common gastroprotective agents are proton pump inhibitors (PPI), H2 blockers, sucralfate, antacids and misoprostol (prostaglandin analogue).

Methods: A cross-sectional, unicentric drug utilization study was conducted. Prescriptions were collected from patients attending the orthopaedic outpatients department. The prescription pattern of NSAIDs, gastroprotective agents or co-administration of NSAIDS and gastroprotective agents were analyzed.

Results: A total of 977 prescriptions were studied; in which 928 prescriptions contained NSAIDs with gastroprotective agents (97.92\%). The most common gastroprotective agents combined with NSAIDs was $\mathrm{H} 2$ receptor blockers (60.56\%), followed by proton pump inhibitors (PPIs) $(21.65 \%)$, while antacids are prescribed least $(17.78 \%)$. Misoprostol or sucralfate were not used at all.

Conclusions: NSAIDs are commonly co-prescribed with gastroprotective agents in high percentage.
\end{abstract}

Keywords: Drug Utilization Study, NSAIDs, Gastroprotective agents

\section{INTRODUCTION}

Non-steroidal anti-inflammatory drugs (NSAIDs) are most commonly used drugs for years for management of pain and inflammation with good efficacy and represent most widely prescribed class of medications in the world and are used as over the counter drugs (OTC). ${ }^{1}$ NSAIDS inhibit cyclooxygenase (COX) enzymes which catalyse the metabolism of arachidonic acid into prostaglandins. COX is available in two isoforms i.e. COX-1 and COX2 . $^{2,3}$ The COX-1 enzyme is constitutive in nature involved in generating prostaglandins for physiological function like gastric mucosal protection, regulation of renal blood flow and platelet homeostasis, while COX-2 has been termed as an inducible enzymes involved in inflammation, colorectal cancer and neurodegenerative disorders. ${ }^{4}$ A new isoform COX-3 has been recently discovered, although its role is yet not clear. ${ }^{5}$

Despite wide clinical use of classical NSAIDs as analgesics, anti-pyretics, and anti-inflammatory agents their gastro-intestinal toxicity (dyspepsia, peptic ulcers and gastrointestinal bleeds) is a major clinical limitation. ${ }^{6}$ Selective COX-2 inhibitors were developed with the aim of minimizing gastrointestinal toxicity, while maintaining anti-inflammatory activity. ${ }^{7}$ However, clinical and experimental data, as well as reviews suggest that the long term use of selective COX-2 inhibitors is associated 
with an increase in systolic blood pressure and cardiovascular morbidity and mortality due to myocardial infarction. ${ }^{8,9}$

The use of NSAIDs is an important predisposing factor for peptic ulcer disease in the community. Approximately $10-20 \%$ of patients who receive long-term NSAID therapy develop asymptomatic peptic ulceration and ulcer-related complications (bleeding and perforation) develop in $1-2 \%$ of persons per year. ${ }^{10}$ This warrants a cautious use of NSAIDs in high risk individuals who include the elderly, those already receiving gastro-toxic agents and those with a history of gastro-intestinal diseases. ${ }^{11}$ So, the best alternative in such individuals would be the co-administration of NSAIDs with gastroprotective drugs. Misoprostol, an analog of prostaglandin E1, has been specifically approved for the prevention of NSAID-induced ulcers in high-risk patients. ${ }^{12,13}$ Proton pump inhibitors too, have been used with outstanding efficacy for this indication.

Drug utilization studies are continuing programmes that review, analyze and interpret the pattern of drug use against pre-determined standards. This drug utilization study was conducted to study the co-administration of non-steroidal anti-inflammatory drugs (NSAIDs) with gastroprotective drugs in an orthopaedics outpatient unit of an urban, tertiary care, teaching hospital. We selected orthopaedics outpatient unit because of frequently prescribed NSAIDs in this department for the management of pain and inflammation.

\section{METHODS}

Ethical considerations: The study protocol, informed consent form (in Bengali, Hindi \& English) and case report form (CRF) were submitted to the ethics committee of College of Medicine \& JNM Hospital, Kalyani, Nadia, West Bengal for approval. Subject recruitment commenced only after approval was obtained. Written informed consent was taken from each participant. Illiterate individuals gave their fingerprint (left thumb impression) instead of signature in the presence of an appropriate witness.

Subject selection criteria: The subjects who had willingly participated were enrolled on the basis of inclusion and exclusion criteria. All the patients using NSAIDs with or without gastroprotective agents, between 18-60 years of age, irrespective of sex, were studied. However, patients who were pregnant, lactating, unable to comply due to mental retardation, unconsciousness or drug addiction were excluded from the study.

Study area: The study was conducted in the Department of Orthopaedics, College of Medicine \& JNM Hospital, Kalyani, Nadia, West Bengal.
Study period: From April 2012 to September 2012.

Study population: The present study was conducted on 977 patients who visited the orthopaedics outpatient unit during the 6-month period.

Study methodology: A cross sectional, unicentric study was conducted in the orthopaedics outpatient department of an urban, tertiary care, medical college hospital in West Bengal during April 2012 to September 2012. Prescriptions were collected from patients attending the orthopaedics outpatients department. The prescription pattern of NSAIDs, gastroprotective agents or coadministration of NSAIDs and gastroprotective agents were analyzed. No follow up of prescription was done.

\section{RESULTS}

In a six months period from April 2012 to September 2012, a total of 977 patients were included in the study and their prescriptions were analyzed only once- no follow up visit was done.

The demographic profiles have been described in Table 1.

Table 1: Demographic characteristics.

\begin{tabular}{|c|c|c|}
\hline $\begin{array}{l}\text { Patient } \\
\text { characteristics }\end{array}$ & $\begin{array}{l}\text { Number of } \\
\text { prescription }\end{array}$ & Percentage $(\%)$ \\
\hline \multicolumn{3}{|l|}{ Age in years } \\
\hline $18-30$ & 178 & 18.21 \\
\hline $31-40$ & 206 & 21.08 \\
\hline $41-50$ & 278 & 28.45 \\
\hline $51-60$ & 315 & 32.24 \\
\hline \multicolumn{3}{|l|}{ Sex } \\
\hline Male & 525 & 53.73 \\
\hline Female & 452 & 46.27 \\
\hline \multicolumn{3}{|c|}{ Male: Female Ratio 1.16:1 } \\
\hline \multicolumn{3}{|l|}{ Diagnosis } \\
\hline Osteoarthritis & 161 & 16.47 \\
\hline $\begin{array}{l}\text { Rheumatoid } \\
\text { arthritis }\end{array}$ & 69 & 07.06 \\
\hline Low backache & 146 & 14.94 \\
\hline $\begin{array}{l}\text { Cervical } \\
\text { spondylosis }\end{array}$ & 129 & 13.2 \\
\hline Postoperative & 186 & 19.03 \\
\hline Trauma & 203 & 20.78 \\
\hline Others & 83 & 08.49 \\
\hline \multicolumn{3}{|c|}{$\begin{array}{l}\text { Prescribing indicators: Average number of drugs } \\
\text { prescription: }\end{array}$} \\
\hline
\end{tabular}

Among the 977 prescriptions with oral NSAIDs, the numbers of prescriptions with gastroprotective agents were $928(94.98 \%)$.

Study design: Cross sectional, unicentric study. 
The gastroprotective agents prescribed were proton pump inhibitors (PPIs) (21.65\%), H2 antagonists (58.31\%) and antacids (18.79\%).

Table 2: Shows different gastroprotective agents.

\begin{tabular}{|lll|}
\hline $\begin{array}{l}\text { Name of the } \\
\text { gastroprotective } \\
\text { agents }\end{array}$ & $\begin{array}{l}\text { Number of } \\
\text { prescription } \\
\text { (Total= 928) }\end{array}$ & $\begin{array}{l}\text { Percentage } \\
(\%)\end{array}$ \\
\hline $\begin{array}{l}\text { Proton Pump } \\
\text { Inhibitors }\end{array}$ & $\mathbf{2 0 1}$ & $\mathbf{2 1 . 6 5}$ \\
\hline Omeprazole & 29 & 3.1 \\
\hline Esomeprazole & 47 & 5.06 \\
\hline Pantoprazole & 71 & 7.65 \\
\hline Rabeprazole & 52 & 5.6 \\
\hline Lansoprazole & 2 & 0.24 \\
\hline H2 Antagonists & $\mathbf{5 6 2}$ & $\mathbf{6 0 . 5 6}$ \\
\hline Famotidine & 428 & 46.12 \\
\hline Ranitidine & 134 & 14.44 \\
\hline $\begin{array}{l}\text { Antacids } \\
\text { Preparation }\end{array}$ & $\mathbf{1 6 5}$ & $\mathbf{1 7 . 7 8}$ \\
\hline Antacid Tab. & 165 & 17.78 \\
\hline
\end{tabular}

None of the other gastroprotective agents were used. The different drugs used in these groups are shown in Table 2.
The use of gastroprotective agents along with the seven commonly used NSAIDs, either as monotherapy or Fixed Drug Combinations (FDC), is shown in Table 3.

The generic prescription of NSAIDs with or without gastroprotective agents are shown in Table 4. Among the drugs, ibuprofen, paracetamol, diclofenac, famotidine, and ranitidine were prescribed in generic form.

\section{DISCUSSION}

When gastric side effects are a cause of concern, non selective COX inhibitors are co-prescribed with an antiulcer agent. The use of selective COX-2 inhibitors seems to have decreased after the cardiac adverse effects which were observed with these drugs. ${ }^{8,9}$ Diclofenac+PCM+Chlorzoxazone, Etoricoxib, Lornoxicam, Piroxicam, PCM+Tramadol were most commonly co-prescribed NSAIDS with a gastroprotective agent- $100 \%$. Ibuprofen was the second most commonly used NSAIDS with a gastroprotective agent- $97.92 \%$. PPIs produce more sustained acid suppression as compared to $\mathrm{H}_{2}$ antagonists and promote ulcer healing despite continued NSAIDS therapy. ${ }^{14,15}$ But in this study, $\mathrm{H}_{2}$ antagonists were the most commonly used gastroprotective agents, followed by proton pump inhibitors. The cause may be due to freely available of $\mathrm{H}_{2}$ antagonists in the hospital pharmacy, it was prescribed more frequently. Antacids were used in least although it was also freely available in hospital. But due to less effective than PPIs and $\mathrm{H}_{2}$ antagonists it was prescribed in fewer amounts.

Table 3: Shows NSAIDs along with gastroprotective agents.

\begin{tabular}{|llllll|}
\hline \multirow{2}{*}{ NSAIDs } & Number of & \multicolumn{3}{c|}{ Co-prescription of antiulcer agents } \\
\hline prescriptions & $\mathrm{N}(\%)$ & $\mathrm{PPI}$ & $\mathrm{H}_{2}$ Blocker & Antacids \\
\hline Ibuprofen & 386 & $378(97.92)$ & 15 & 298 & 65 \\
\hline Paracetamol (PCM) & 57 & $50(87.71)$ & 08 & 06 & 36 \\
\hline Aceclofenac & 109 & $100(91.74)$ & 29 & 60 & 11 \\
\hline Aceclofenac+PCM & 89 & $86(96.62)$ & 37 & 49 & 25 \\
\hline Diclofenac & 90 & $85(94.45)$ & 25 & 35 & \\
\hline Diclofenac+PCM & 65 & $65(100)$ & 24 & 41 & 18 \\
\hline Diclofenac+PCM+Chlorzoxazonone & 46 & $46(100)$ & 36 & 10 & 5 \\
\hline Etoricoxib & 47 & $30(62.82)$ & 2 & 13 & 3 \\
\hline Lornoxicam & 29 & $29(100)$ & 11 & 22 & 2 \\
\hline Piroxicam & 34 & $34(100)$ & 09 & 18 & 25 \\
\hline PCM+Tramadol & 25 & $25(100)$ & 05 & & \\
\hline
\end{tabular}

Antacids are indicated only for symptomatic relief of pain and are associated with a number of drug interactions, thereby restricting their use. ${ }^{11}$ Misoprostol, the drug indicated for the prophylaxis of high risk individuals, were not used at all. This may be because of various reasons including the higher cost, frequent side effects and the need for multiple daily dosing of Misoprostol. In any case, similar or even better efficacy is obtained by proton pump inhibitors in preventing and/or treating NSAID-induced peptic ulcers. ${ }^{16,17}$ There was no prescription of sucralfate as gastroprotective agents.

The drugs like Ibuprofen, Paracetamol (PCM), Diclofenac, Famotidine and Ranitidine that were supplied 
in hospital at free of cost, were prescribed in generic form in $100 \%$ cases but the other drugs were not prescribed generically in such high percentage.

Table 4: Shows the number of drugs prescribed in generic form.

\begin{tabular}{|llll|}
\hline Name of drugs & $\begin{array}{l}\text { Number } \\
\text { of } \\
\text { prescripti } \\
\text { ons }\end{array}$ & $\begin{array}{l}\text { Prescrip } \\
\text { tion in } \\
\text { generic } \\
\text { form }\end{array}$ & $\begin{array}{l}\text { Percenta } \\
\text { ge }(\%)\end{array}$ \\
\hline Ibuprofen & 386 & 386 & 100 \\
\hline Paracetamol & 57 & 57 & 100 \\
\hline Diclofenac & 90 & 90 & 100 \\
\hline Etoricoxib & 47 & 2 & 4.25 \\
\hline Aceclofenac & 109 & 12 & 11 \\
\hline Famotidine & 428 & 428 & 100 \\
\hline Ranitidine & 134 & 134 & 100 \\
\hline Omeprazole & 29 & 9 & 31.03 \\
\hline Esomeprazole & 47 & 6 & 12.77 \\
\hline Pantoprazole & 71 & 12 & 16.9 \\
\hline Rabeprazole & 52 & 7 & 13.46 \\
\hline
\end{tabular}

\section{CONCLUSION}

To conclude, our study shows that nonselective COX inhibitors more commonly preferred analgesics than COX-2 inhibitors. NSAIDs were commonly co-prescribed with gastroprotective agents in a high percentage, and $\mathrm{H}_{2}$ blockers are the most common gastroprotective agents used simultaneously with NSAIDs.

\section{Funding: No funding sources}

Competing interests: None declared

Ethical approval: The study was approved by the ethics committee of College of Medicine \& JNM Hospital, Kalyani, Nadia, West Bengal

\section{REFERENCES}

1. Sharma T, Dutta S, Dhasmana DC. Prescribing Pattern of NSAIDs in Orthopaedic OPD of a Tertiary Care Teaching Hospital in Uttaranchal. JK Sci 2006;8:160-2.

2. Vane JR. Inhibition of prostaglandin synthesis as a mechanism of action for aspirin like drugs. Nat New Biol 1971;231:232-5.

3. Warner TD, Mitchell JA. Cyclooxygenase: new forms, new inhibitors and lessons from the clinic. FASEB J 2004;18:790-804.

4. Marnett LJ, Rowlinson SW, Goodwin DC, Kalgutkar AS, Lanzo CA. Arachidonic acid oxygenation by COX-1 and COX-2. Mechanisms of catalysis and inhibition. J Biol Chem 1999;274:22903-6.

5. Chandrasekharan NV, Dai H, Roos KC, et al. COX3,a cyclooxygenase-1 variant inhibited by acetaminophen and other analgesic/antipyretic drugs: cloning, structure and expression. Proc Natl Acad Sci USA 2002;99:13926-31.

6. Graumlich JF. Preventing gastrointestinal complications of NSAID's: risk factors, recent advances, and latest strategies. Postgrad Med 2001;109:117-28.

7. Hawkey CJ. COX - 2 inhibitors. Lancet 1999;353:307-14.

8. Mukherjee D, Nissen SE, Topol EJ. Risk of cardiovascular events associated with selective COX-2 inhibitors. JAMA 2001;286:954-9.

9. Jain S, Gupta M, Malhotra S, Pandhi P. Effect of Rofecoxib on antihypertensive effects of Candesartan in experimental models of hypertension. Methods Find Exp Clin Pharmacol 2005;27:11-6.

10. McQuaid KR. Drugs used in the treatment of Gastrointestinal Diseases. In: Katzung BG, editor. Basic and Clinical Pharmacology, 10th ed. McGraw Hill; 2007:1009-19.

11. Raghavendra B, Sanji N, Ullal SD, et al. Trends in Prescribing Gastroprotective Agents with Non Steroidal Anti-Inflammatory Drugs in an Orthopaedic Outpatient Unit of a Tertiary Care Hospital. J Clin Diagn Res 2009;3:1553-6.

12. Hopkinson N, Doherty M. NSAIDS-associated gastropathy- a role for misoprostol? Br J Rheumatol 1990;29:133-6.

13. Walt RP. Misoprostol for the treatrment of peptic ulcer and antiinflamatory-drug induced gastroduodenal ulceration. $\mathrm{N}$ Engl J Med 1992;327:1575-80.

14. Gisbert JP, Gonzalez L, Calvet X, Roque M, Gabriel R, Pajares JM. Proton pump inhibitors versus H2antagonists: a meta-analysis of their efficacy in treating bleeding peptic ulcer. Aliment Pharmacol Ther 2001;15:917-26.

15. La Corte R, Caselli M, Castellino G, Bajocchi G, Trotta F. Prophylaxis and treatment of NSAIDinduced gastroduodenal disorders. Drug Saf 1999;20:527-43.

16. Dupas JL, Grigy C. Curative and preventive treatment of NSAID-associated gastroduodenal ulcers. Gastroenterol Clin Biol 2004;28:C77-83.

17. Lazzaroni M, Porro GB. Management of NSAIDinduced gastrointestinal toxicity: focus on proton pump inhibitors. Drugs 2009;69:51-69.

doi:10.5455/2319-2003.ijbcp20130315

Cite this article as: Kumar A, Dalai CK, Ghosh AK, Ray M. Drug utilization study of co-administration of nonsteroidal anti-inflammatory drugs and gastroprotective agents in an orthopaedics outpatients department of a tertiary care hospital in West Bengal. Int J Basic Clin Pharmacol 2013;2:199-202. 